\title{
Design of Automatic Bottle Filling Using Raspberry Pi
}

\author{
Hadyan Arifianto ${ }^{1}$, Kusworo Adi ${ }^{1}$, Catur Edi Widodo ${ }^{1}$ \\ 1 Department of Physics, Faculty of Science and Mathematics, Diponegoro University, Semarang
}

\section{A R T I C LE I NFO}

Article history:

Received : September 2018

Accepted : November 2018

Available online : November 2018

\section{Keywords:}

Raspberry Pi

Control system

Solenoid valve

Automatic bottle filling

\begin{abstract}
A B S T R A C T
Water consumption is very high, especially in urban areas. This means a good business opportunity for small and medium enterprises. Those enterprises, therefore, require an automatic and affordable device that can fill water into bottles. Raspberry Pi is the center of the control system in designing this automatic bottle filling device. This is because Raspberry Pi comes a with GPIO pin that is used as an input-output controller. GPIO pin receives signal input from switches and sensors that are then processed using Python programming language to drive an actuator and a solenoid valve. Subsequent hardware testing includes tests for water sensor, director motor, alternating motor, and solenoid valve. It is found that the water sensor works at a voltage of $4.18 \mathrm{~V}$ and that The DC motor works at $13.92 \mathrm{~V}$. It is also found that the DC motor moves back and forth at $34.77 \mathrm{~V}$ when it is moving up, and at $-34.77 \mathrm{~V}$, when it is moving down. Meanwhile, the solenoid valve is found to work at $224.9 \mathrm{~V}$. Therefore; it's very possible to use Raspberry Pi as the center of a control system for an automatic bottle filling device.
\end{abstract}

\section{Introduction}

Water is essential for the survival of human beings. Water makes up $75 \%$ person of the human body. On the other hand, the population of the world is steadily growing. This makes the need for clean water ever increasing. There is now, even more, need to carry clean water around easily. Meeting this need require mass production of bottled water within a short time as possible.

Technological advancement allows for automatic bottle filling with the help of a microcontroller. With automation, product quantity and quality can be improved, and in turn, profit will rise. Automatic control functions to compare actual value from plant output to reference input (desired value), determine deviation, and produce a control signal that will reduce zero deviation or small value. The way a controller generates automatic control is known and control action [1, 2, 3, 4, 5].

Construction of an automatic control can make use Raspberry $\mathrm{Pi}$ as the control center. This is because Raspberry Pi comes with the high inputoutput capability and it is also supported by onboard memory and Ethernet [6].

Unlike an ordinary computer or microcontroller, Raspberry is equipped with a 40-pin GPIO system that serves as sensor input-output and regulator to actuators. Raspberry can also be used for image processing systems as it has sufficient microprocessor and RAM that allows Raspberry to process data. Desktop display and keyboard functions that are similar to Windows platform ease Raspberry Pi operation [6].

\section{Theory}

A control system is interconnections among components that make up a system configuration which provides desired system response. This means that components can be controlled based on the input-output relationship of processes. Hence, a control system processes input signals to generate output signal variables.

Automatic control functions to compare actual value from plant output to reference input (desired value), determine deviation, and produce a control signal that will reduce zero deviation or small value. The way a controller generates automatic control is known and control action. A controller detects actuator error signals, usually at a very low voltage, and attenuates them to reasonably higher levels. The output of an automatic controller is fed to an actuator, which is an electrical instrument generating input to the plant according to the control signal, to allow output signal to be similar with reference input signal $[1,4]$.

A feedback control system is often referred to as a closed loop control system. In practice, both terms are used interchangeably. In a closed loop control system, an actuator error signal - the difference between input and feedback signals (the output signal itself or its function, derivative, and integral) is fed to the controller to reduce error and to give system output the desired value. The closed loop 
control always implies a feedback control measure to reduce system error $[1,4]$.

The advantage of closed-loop control is the use feedback value that makes control response less sensitive to external interferences and internal changes to control parameters. However, the disadvantage is preventive reparation against interference is not possible before the latter already affects process values [4].

Raspberry $\mathrm{Pi}$ model $\mathrm{B}$ has $1 \mathrm{~GB}$ RAM. It is equipped with $900 \mathrm{MHz}$ quad-core ARM Cortex-A7 CPU. Raspberry Pi2 also comes with four USB ports. These ports can be used as interfaces for the camera, keyboard, and Wi-Fi dongle. Raspberry $\mathrm{Pi} 2$ also provides one LAN port for communication. Other than those, it features a 40-pin GPIO for input and output. Another feature is one HDMI port [6, 7].

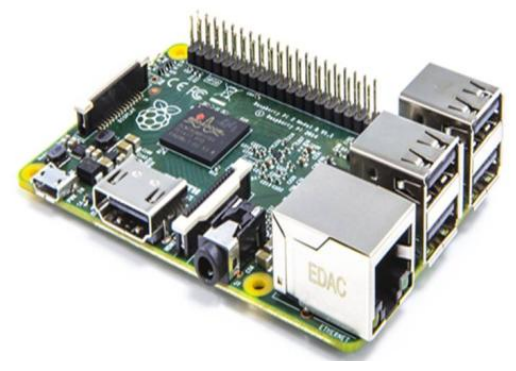

Figure 1. Raspberry Pi 2

The 40-pin GPIO allows Raspberry Pi to be connected to electronic components or sensors. Each pin has different functions. Of the 40 pins, Raspberry $\mathrm{Pi} \mathrm{B}+\mathrm{has}$, two pins serve as the source of $5 \mathrm{~V}$ voltage, two pins act as the source of $3.3 \mathrm{~V}$ voltage, eight pins are the ground, 26 pins are the GPIO and two pins functions as a series, as shown in Figure 2.5. GPIO pins enable function adjustment as required, either as input or output. GPIO pins will serve as a signal receiver from sensors (as input) or provide signals to the other electronic components (as output) [6].

Python is a freeware programming language for just about everyone. It does not have a limitation regarding copying or distribution. And Python is the official programming language of Raspberry Pi. The word "Pi" in Raspberry Pi stems from Python. Hence, Python is the original language of Raspberry Pi. Other than in Raspberry, Python can also be accessed via some operating systems such as Windows, Macintosh, DOS, Nokia Mobile Phone, and many other [8].

A relay is an automatic switch that operates using electromagnetic principles. One of its functions is to isolate the electric system, and it is connected mechanically. The switch in a relay comprises input and output parts. The input has a coil that generates a magnetic field at low voltage. The output has a connecting rod that connects and disconnects mechanically [9].

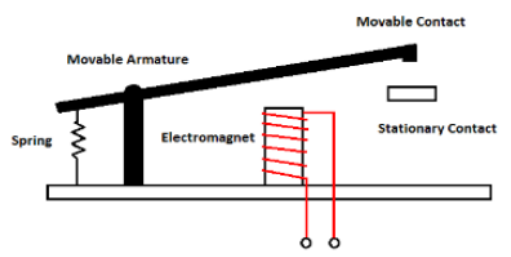

Figure 2. A simple relay scheme
The main part of a relay is the sensing unit that is an electric coil. AC or DC voltage is used to turn this coil on. When current or voltage increases beyond a threshold, relay armature is activated by the coil that functions to connect and disconnect current. The switch mechanism is operated by the magnetic force generated when the coil is supplied with power. As the coil is energized, it sends information to the switch that makes it connected. The relay compares the current or voltage from the connected transformer and sends information to the switch [9].

Solenoid valve requires electric energy in its operation to control water or gas. The valve is opened and closed under the control of solenoid, which has an electric coil with a ferromagnetic core at the center when current is available. The ferromagnetic core is also known as the plunger. A plunger closes the hole when no current is flowing to the coil. When current is available, the coil generates a magnetic field and this, in turn, provides thrusting force to pull it to the center to open the hole [10].

A DC motor requires a direct power supply in the coil field to turn it into mechanical energy. There are two coils in a DC motor; the field coil that functions to generate a magnetic field and the anchor coil that functions to facilitate electromotive force.

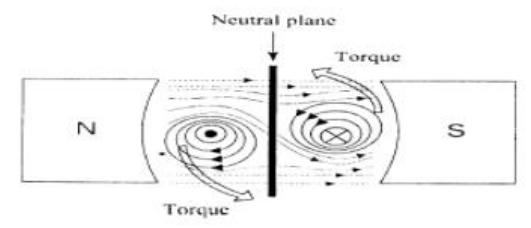

Figure 3. The direction of motor rotation depends on magnetic polarity on the wire.

DC motor axis may rotate either clockwise or anti-clockwise. Determining the direction of motor rotation can be done as shown in Figure 2.9. Sign (x) denotes electron current away from us and sign $(\bullet)$ denotes electron current towards us. The big arrow indicates the direction of anti-clockwise axis rotation. When the axis is perpendicular to the main magnetic flux, no magnetic field reaction between the axis flux and the main magnetic flux takes place. However, due to the moment of inertia, the axis keeps on spinning [11].

\section{Methods}

Figure 4 shown a block diagram of Automatic Bottle Filling Using Raspberry Pi. Raspberry Pi serves as the control center of the system. Meanwhile, relay driver functions as an output switch. The one in charge of output is the DC motor on the conveyor belt, solenoid valve, and DC motor on the funnel. An Optocoupler circuit is used for input to Raspberry Pi pin, which means that input credit from components is not directly connected to GPIO pin, to prevent short-circuiting that may otherwise affect Raspberry Pi.

As the start button is pushed, the conveyor belt runs and moves empty bottles. The conveyor stops when a bottle passes the photodiode. At this time, the funnel lowers to the bottle tip to allow water to get into the bottle, without any spill over. Bottle filling with water continues until the bottle touches 
the limit switch on the funnel. That indicates if the bottle is filled. Once the bottle is filled, the funnel moves away from the bottle tip. This up and down movement of the funnel is regulated by a DC motor, whose polarization is adjusted as to allow up and down movement. The limit for the funnel's up and down movement is the limit switch that is attached as such, as to allow the funnel to stop on the bottle tip as it lowers, and to go up as it hits the upper limit switch.

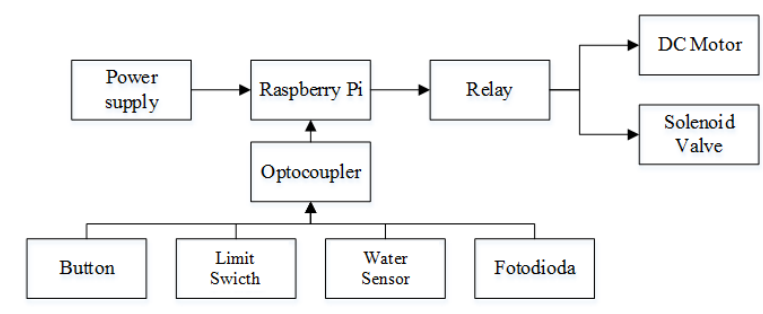

Figure 4. Block diagram of Automatic Bottle Filling Using Raspberry Pi

\section{Result and Discussion}

Sensor testing was performed by adding a switch circuit on the full water sensor that is connected by a relay to Raspberry Pi. Using BC559 transistor, BC107 transistor, and relay configuration as shown in Figure 5, output signals are recognizable by Raspberry Pi, with the relay serving as an automatic switch.

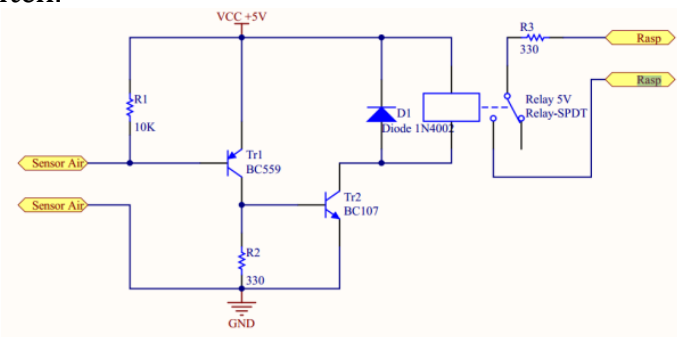

Figure 5. A switch circuit for the water sensor.

Table 1 provides measurement results from water sensor testing.

Table 1.Results of waster sensor testing

\begin{tabular}{|c|c|c|}
\hline No. & Condition & Voltage (V) \\
\hline 1 & Touches the water & 4.19 \\
\hline 2 & Touches the water & 4.19 \\
\hline 3 & Touches the water & 4.18 \\
\hline 4 & Touches the water & 4.15 \\
\hline 5 & Touches the water & 4.20 \\
\hline 6 & $\begin{array}{c}\text { Does not touch the } \\
\text { water }\end{array}$ & 0.00 \\
\hline 7 & $\begin{array}{l}\text { Does not touch the } \\
\text { water }\end{array}$ & 0.00 \\
\hline 8 & $\begin{array}{l}\text { Does not touch the } \\
\text { water }\end{array}$ & 0.00 \\
\hline 9 & $\begin{array}{c}\text { Does not touch the } \\
\text { water }\end{array}$ & 0.00 \\
\hline 10 & $\begin{array}{l}\text { Does not touch the } \\
\text { water }\end{array}$ & 0.00 \\
\hline
\end{tabular}

Testing was performed by measuring sensor voltage on both conditions; when it touches the water and when it does not touch the water. Results show that this sensor works an average voltage of $4.18 \mathrm{~V}$, and when it does not touch the water, the reading is 0.00 .

Testing was performed using a switch connected to Raspberry Pi and a relay (serving as a switch) that connects Raspberry $\mathrm{Pi}$ to the DC motor. The DC motor used works at $12 \mathrm{~V}$. Results of DC motor testing are given in Table 2.

\begin{tabular}{|c|c|c|}
\hline No. & Condition & Voltage (V) \\
\hline 1 & $\mathrm{ON}$ & 14.02 \\
\hline 2 & ON & 14.13 \\
\hline 3 & ON & 14.08 \\
\hline 4 & ON & 13.31 \\
\hline 5 & ON & 14.05 \\
\hline 6 & OFF & 0.00 \\
\hline 7 & OFF & 0.00 \\
\hline 8 & OFF & 0.00 \\
\hline 9 & OFF & 0.00 \\
\hline 10 & OFF & 0.00 \\
\hline
\end{tabular}

The alternating DC motor is mounted vertically to allow lowering and raising of bottle filling funnel. This DC motor works at $24 \mathrm{~V}$. Two relays that create an $\mathrm{H}$ bridge relay are used to reverse its movement to up and down. The $\mathrm{H}$ bridge relay allows DC motor to reverse its polarity. Using two buttons, one button functions to raise the funnel, while the other functions to lower it.

Results show that the average voltage when the funnel is raised is $34.77 \mathrm{~V}$, whereas when the funnel is lowered, the average voltage is $-34.83 \mathrm{~V}$. The negative sign on the millimeter reading indicates polarity reversal of the DC motor. Complete results of this test are given in Table 3 .

Table 3. Results of alternating DC motor testing

\begin{tabular}{ccc}
\hline No. & Condition & Voltage (V) \\
\hline 1 & Upward & 34.74 \\
2 & Upward & 34.79 \\
3 & Upward & 34.74 \\
4 & Upward & 34.80 \\
5 & Upward & 34.76 \\
6 & Downward & -34.85 \\
7 & Downward & -34.86 \\
8 & Downward & -34.80 \\
9 & Downward & -34.80 \\
10 & Downward & -34.86 \\
11 & OFF & 0.00 \\
12 & OFF & 0.00 \\
13 & OFF & 0.00 \\
14 & OFF & 0.00 \\
15 & OFF & 0.00 \\
\hline
\end{tabular}

Solenoid valve works at $220 \mathrm{~V}$ of $\mathrm{AC}$, and it is connected to a driver relay to prevent direct connection to Raspberry Pi pins. This is because the relay isolates the Raspberry from the other components. Testing was performed using two switches. One switch functions to turn on the solenoid valve, while the other functions to turn it off. Testing was also performed to find out if there is a leak during valve installment on the water reservoir and also on the hose leading to the funnel. 
Results show the average voltage of the solenoid valve to be $224.9 \mathrm{~V}$. Measured voltages when the solenoid valve is turned on and off are given in Table 4.

\begin{tabular}{|c|c|c|}
\hline No. & Condition & Voltage (V) \\
\hline 1 & ON & 224.9 \\
\hline 2 & ON & 225.1 \\
\hline 3 & ON & 224.9 \\
\hline 4 & ON & 224.9 \\
\hline 5 & $\mathrm{ON}$ & 224.8 \\
\hline 6 & OFF & 0.00 \\
\hline 7 & OFF & 0.00 \\
\hline 8 & OFF & 0.00 \\
\hline 9 & OFF & 0.00 \\
\hline 10 & OFF & 0.00 \\
\hline
\end{tabular}

Once testing for each section is done, the next step was to test the system as a whole. To ensure the system works as desired, each section is placed as shown in Figure 6.

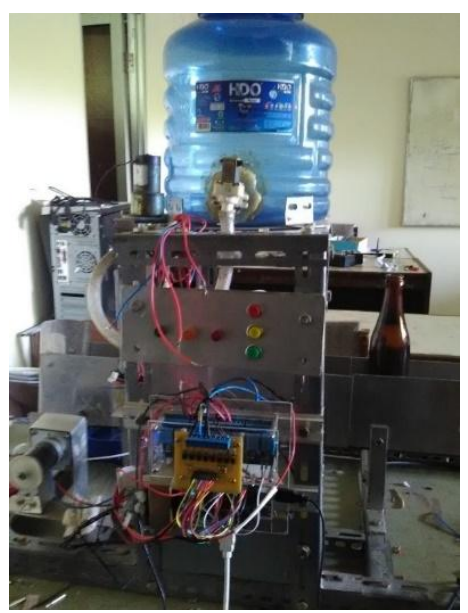

Figure 6. Automatic bottle filling device

The system works as follow: when the start button is pushed, the conveyor belt moves bottles to the filling spot. Each bottle stops at the spilling spot in turn as it covers the photodiode. At this time, the funnel lowers until it touches the lower limit switch and stops. The solenoid valve then opens, and the water flows down to the bottle via the funnel until the water touches the full water sensor attached on the funnel. As the sensor senses water, it sends a signal that shuts the solenoid valve down, and the funnel moves up away from the bottle tip and stops as it touches the upper limit switch. Afterward, the bottle is moved to the final spot by the conveyor belt, as the same processes restart over and over again for the subsequent bottles.

\section{Conclusion}

Results show that the use of Raspberry Pi as the center of a control system for bottle filling is very probable. This is facilitated by the GPIO embedded in Raspberry that functions as input and output. Testing results reveal that average voltage working on the sensor that touches water is $4.18 \mathrm{~V}$ and that the value is $0 \mathrm{~V}$ when the sensor does not touch the water. Meanwhile, solenoid valve works at an average voltage of $224.9 \mathrm{~V}$. It is also found that the direct DC motor used works at $13.92 \mathrm{~V}$. Whereas the alternating DC motor works at $34.77 \mathrm{~V}$ when it raises, and at -34.82 when it lowers.

\section{References}

1 Dorf, R., and Bishop, R., 2011, Modern Control System, Vol. 12, Pearson Education, Inc., New Jersey.

2 Das,T.K. and Das, Y., 2013, Design of A Room Temperature And Humidity Controller Using Fuzzy Logic, American Journal of Engineering Research (AJER), Volume-02, Issue-11, pp - 8697.

3 Hashim, A., and Ahmed, 0., 2012, HighPerformance Speed Control of Direct Current Motors Using Adaptive Inverse Control, WSEAS Transactions on System and Control, Issue 2, Volume 7 .

4 Ogata, K., 2010, Modern Control Engineering, Vol. 5, Pearson Education, Inc., New Jersey.

5 Shah, V., and Bhatt, K., 2016, Image Processing Based Bottle Filling and Label Checking Embedded System, International Journal of Innovative Research in Computer and Communication Engineering, 4, 5, 9778-9787.

6 Rao, P. B. and Uma, S.K., 2015, Raspberry Pi Home Automation With Wireless Sensor Using Smart Phone, International Journal of Computer Science and Mobile Computing, Vol.4 Issue.5, pp. 797 - 803.

7 Sobota,J., Pisl,R., Balda,P., Schlegel,M., 2013, Raspberry $\mathrm{Pi}$ and Arduino boards in control education, IFAC Proceedings Volumes, Vol. 46, no 17 , pp. 7-12.

8 Fangohr, H., 2015, Introduction to Python for Computational Science and Engineering, Faculty of Engineering and the Environment University of Southampton.

9 Verma, N., Gupta, K., and Mahapatra, S., 2015, Implementation of Solid State Relays for Power System Protection, International Journal of Scientific and Technology Research, Vol. 4, Issue 6, 66-70.

10 Sidik, M., and Ghani, S. C., 2017, Volume Measuring System Using Arduino for Automatic Liquid Filling Machine, International Journal of Applied Engineering Research, 12, 1450514509.

11 Chapman, S.J., 2005, Electrical Machinery Fundamentals $4^{\text {th }}$ Ed, McGraw Hill, New York. 